\title{
Epidemiological and clinical factors impact on the benefit of riluzole in the survival rates of patients with ALS
}

\author{
Impacto de fatores epidemiológicos e clínicos sobre o benefício do riluzol nas taxas de \\ sobrevida de pacientes com ELA \\ Francis Meire Fávero', Mariana Callil Voos², Isac de Castro³, Fátima Aparecida Caromano², Acary Souza \\ Bulle Oliveira ${ }^{1}$
}

\begin{abstract}
Objective: To investigate the impact of epidemiological and clinical factors on the benefit of riluzole in patients with amyotrophic lateral sclerosis (ALS). Methods: The survival rate of 578 patients with ALS (1999-2011) was analyzed by descriptive statistics and Kaplan-Meier curves. Considering the median of the sample survival time (19 months), patients were divided in two groups: below (B19) and above the median (A19). Kaplan-Meier curves compared the survival rates of patients treated with riluzole and with patients who did not take the medication. Results: Riluzole increased the survival rates of patients with lower limb onset who were diagnosed after the first appointment in B19. Patients with bulbar onset and diagnosed on the first, or after the first appointment showed higher survival rates in A19. Males lived longer than females in both groups. Conclusion: Epidemiological and clinical factors influenced the benefit of riluzole in the survival rates of patients with ALS.
\end{abstract}

Keywords: epidemiology; amyotrophic lateral sclerosis; motor neuron disease; survival; riluzole

RESUMO

Objetivo: Investigar o impacto de fatores epidemiológicos e clínicos sobre o benefício do riluzole em pacientes com esclerose lateral amiotrófica (ELA). Métodos: A sobrevida de 578 pacientes com ELA (1999-2011) foi analisada por estatística descritiva e curvas de Kaplan-Meier. Considerando a mediana do tempo de sobrevida (19 meses), a amostra foi subdividida em dois grupos: sobrevida abaixo (B19) e acima de 19 meses (A19). As curvas de Kaplan-Meier compararam a sobrevida de pacientes tratados com riluzole e com pacientes que não receberam tratamento. Resultados: O riluzole aumentou a sobrevida de pacientes com início nos membros inferiores e diagnosticados após a primeira consulta no grupo B19. Pacientes com início bulbar e diagnosticados na primeira/ após a primeira consulta apresentaram maior sobrevida em A19. Os homens apresentaram sobrevida maior do que as mulheres. Conclusão: Foram encontradas diferenças epidemiológicas e clínicas no benefício do riluzole em pacientes com ELA.

Palavras-chave: epidemiologia; esclerose amiotrófica lateral; doença dos neurônios motores; sobrevivência; riluzole.

Amyotrophic lateral sclerosis (ALS) results from the degeneration of upper and lower motor neurons. The life expectancy of a person with ALS averages two to five years from the time of diagnosis. However, large variability is observed, according to the initial symptoms ${ }^{2}$. A higher incidence of ALS among men is noted ${ }^{1,2,3,4,5}$ and can be explained by a higher proportion of men exposed to toxins at work $\mathrm{k}^{1,3,6,7}$.

The ALS diagnosis is related to the history and progression of the disease. It may be difficult to diagnose early because it may mimic several other neurological diseases. Tests to rule out other conditions may include electromyography, nerve conduction studies, magnetic resonance imaging (MRI), blood and urine tests, lumbar puncture and muscle biopsy. The diagnoses requires: 1) the presence of signs of lower motor neuron degeneration in clinical, electrophysiological or neuropathologic examination; 2) signs of upper motor neuron degeneration in the clinical examination, and 3) progressive spread of signs within

\footnotetext{
'Universidade Federal de São Paulo, Departamento de Neurologia e Neurocirurgia, São Paulo SP, Brasil;

${ }^{2}$ Universidade de São Paulo, Faculdade de Medicina, Departamento de Fisioterapia, Fonoaudiologia e Terapia Ocupacional, São Paulo SP, Brasil;

${ }^{3}$ Universidade de São Paulo, Faculdade de Medicina, Departamento de Nefrologia, São Paulo SP, Brasil;

Correspondence: Francis Meire Fávero; Rua Botucatu, 740; 04023-062 São Paulo SP, Brasil; E-mail: ffave.nexp@latoneuro.com.br

Conflict of interest: There is no conflict of interest to declare.

Received 29 January 2017; Received in final form 31 March 2017; Accepted 15 April 2017.
} 
a region or to other regions, together with the absence of electrophysiological evidence of other processes that might explain the degeneration; and neuroimaging evidence of other processes that might explain the clinical and electrophysiological signs ${ }^{8}$.

The time interval between the first symptoms and the diagnosis influences the ALS prognosis ${ }^{9}$. In the early stages, symptoms may go unrecognized and undiagnosed. Muscles may be weak or spastic and cramping and fasciculations may occur, as atrophy progresses. Symptoms are usually limited to a single body region or mild symptoms may affect more than one region. The patient may experience fatigue, gait instability, changes in speed or rhythm during speech, and a weak hand grip. Survival time after diagnosis is variable in the literature (from eight to 66 months) $)^{5,67,9,10,11,12,13,14,15,16,17,18,19,20,21,22}$. In general, shorter intervals from symptom onset to diagnosis predict lower survival rates.

Riluzole is the only treatment that increases the survival rate of patients with ALS. Models in vitro, after excitotoxic action in motor neurons, showed the regression of lesions and the reduction of glutamatergic spontaneous events. Patients with bulbar onset benefited more from riluzole administration than patients with limb onset ${ }^{9,15}$. However, lower limb onset is usually associated with higher survival rates than the upper limb onset and bulbar forms ${ }^{7,15}$. The use of noninvasive ventilation improves the prognosis of ALS patients, because it compensates for respiratory muscle weakness ${ }^{23}$. Gastrostomy feeding provides long-term nutritional support for patients with dysphagia ${ }^{23}$.

The present study aimed to investigate the effect of riluzole on the survival rates of patients with ALS in one Brazilian center, considering epidemiological (age, gender and race) and clinical aspects (initial symptoms topography, time from first symptoms to neurologic evaluation, time from first symptoms to electromyography, time from first symptoms to diagnosis).

Considering the epidemiological factors, we believed that older patients and males would show lower survival rates and that a higher incidence would be found among whites. Considering the clinical aspects, we hypothesized that patients showing lower limb initial symptom topography would show higher survival rates. In these cases, the time to progression of weakness or spreading would be longer than in patients with upper limb, or bulbar, onset. We also hypothesized that patients with a longer time interval from first symptoms to neurologic evaluation, electromyography and/or diagnosis would show higher survival rates. In these cases, we supposed that early stage ALS would last longer, with slower progression and, consequently, a higher survival rate. We hypothesized that patients treated with riluzole would show higher survival rates than patients who did not take the medication.

\section{METHODS}

This was a prospective cohort study. It was approved by the Ethics Committee of Federal University of São Paulo. During the 12-year study period (from 1999-2011), we identified patients in the Motor Neuron Disease Clinic from the Clinical Investigation on Neuromuscular Diseases Section, Department of Neurology and Neurosurgery of the Federal University of São Paulo. These patients received an ALS diagnosis, according to the El Escorial of World Federation of Neurology Research Group on Neuromuscular Diseases criteria ${ }^{8}$.

We collected epidemiological, clinical and therapeutic data from charts. Epidemiological variables consisted of age, gender and race. Clinical data included initial symptoms topography, time from first symptoms to neurologic evaluation, time from first symptoms to diagnosis (before, at or after the first appointment with the neurologist), the moment when electroneuromyography was solicited (at or after the first appointment) and the survival rate (from diagnosis to death). Therapeutic data were registered if riluzole and non-invasive ventilation were prescribed or not. All patients received interdisciplinary treatment (neurologist, occupational therapist, motor and respiratory physical therapist, psychologist, nutritionist and social assistant) and differed only in whether the patient received riluzole or not.

\section{Statistical analysis}

Continuous and semicontinuous data were initially compared in a Gauss curve with the Kolmogorov-Smirnov test. Non-parametrical data were represented by the median and percentiles and compared by Mann-Whitney tests. Categorical data were represented by absolute (n) and relative (\%) frequencies and analyzed by Chi-square tests. The survival rate was analyzed by Kaplan-Meier curves and represented by medians of survival estimations and standard errors of estimations. Comparisons between survival curves were made using the log-rank test. All comparisons considered the alpha risk below 5\% as type I error and below $20 \%$ as type II error. The SPSS 19.0 was used in all analyses.

\section{RESULTS}

Charts from 1,146 patients with motor neuron diseases were analyzed. Of the 578 charts meeting the El Escorial diagnosis criteria for ALS, 231 had the date of death available. These 231 patients were included and the impact of epidemiological and clinical characteristics on the benefit of riluzole on the survival rate was investigated.

Kaplan-Meier curves are based on life expectancy. The median of survival time was 19 months. The survival curves included 144 patients who survived from one to 19 months after ALS diagnosis (survival time below 19 months: B19) and 87 patients who survived longer than 19 months after ALS diagnosis (survival time above 19 months: A19) (Figure 1). 


\section{Epidemiological characteristics}

Considering the total sample, $56.1 \%$ were males $(\mathrm{n}=131)$, with the ratio male: female of 1.32:1 $(\mathrm{p}=0.001)$. Ethnicity was 90\% Caucasian ( $\mathrm{n}=209)$, $9 \%$ African $(\mathrm{n}=19)$ and $1 \%$ Asian $(n=3)$. All cases were sporadic. The medians of age were 63 years in B19 and 57 years in A19 $(\mathrm{p}<0.050)$.

\section{Clinical characteristics}

The moment of the diagnosis influenced the survival rate. In the A19 group, patients diagnosed after the first appointment with the neurologist lived longer (21.1 months, $p=0.029$ ), compared to the ones diagnosed

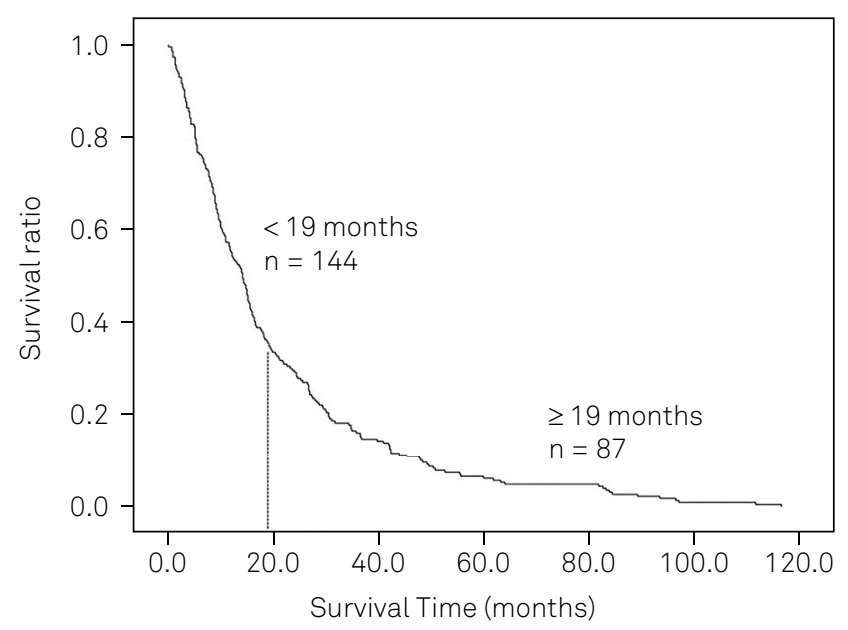

Figure 1. Survival time. before the first appointment with the neurologist, by a physician with another specialty (17.4 months, $p=0.157)$, and compared to the ones diagnosed on the first appointment (13.7 months, $\mathrm{p}=0.361$ ).

Considering the electromyography, seven patients were not submitted to the exam before the first appointment with the neurologist. These patients lived longer (18.4 months) than the ones submitted to the exam before the first appointment (15.9 months).

The Table shows the medians of the time from the first symptoms to the diagnosis and total survival time (from early symptoms to death), followed by a comparison with other studies. The time between the first symptoms and the first appointment varied from nine to 26 months, with a median of 16 months, considering the whole group, 15 months in the B19 group and 13 months in the A19 group.

\section{Riluzole treatment}

In the B19 group ( $\mathrm{n}=144), 82$ patients $(56.9 \%)$ were treated with riluzole and in the A19 group $(\mathrm{n}=87), 53$ patients (60.9\%) received the drug. Riluzole influenced the survival rate of the A19 group, but not of the B19 group. In the B19 group, the median survival of patients receiving riluzole was 4.5 months. The median survival time of patients who did not receive the drug was 3.4 months ( $p=0.176$ ) (Figure 2A). Patients treated with riluzole lived longer than the patients who were not treated with this drug (18.3 versus 13.7 months, $\mathrm{p}=0.001)$ (Figure 2B).

Table. Time intervals (median, in months) between the first symptoms and the diagnosis, and between the diagnosis and death.

\begin{tabular}{|c|c|c|c|c|c|}
\hline Authors & Year & $\begin{array}{l}\text { First symptoms to } \\
\text { diagnosis }\end{array}$ & Range & $\begin{array}{l}\text { Diagnosis to death } \\
\text { (survival) }\end{array}$ & Range \\
\hline Dietrich-Neto ${ }^{10}$ & 2000 & 11 & $0-332$ & 42 & $7-191$ \\
\hline Tomik ${ }^{11}$ & 2000 & NM & NM & 38 & $10-218$ \\
\hline Aguila $^{9}$ & 2003 & 32 & NM & 19 & NM \\
\hline Traynor ${ }^{12}$ & 2003 & 10 & $1-110$ & NM & NM \\
\hline Forbes $^{13}$ & 2004 & 15 & Jun-17 & 28 & $17-50$ \\
\hline Mandrioli ${ }^{7}$ & 2006 & 9 & NM & 29 & NM \\
\hline Beghi ${ }^{14}$ & 2006 & 39 & NM & 30 & NM \\
\hline Zoccolella ${ }^{15}$ & 2007 & 8 & Jan-70 & 18 & Jan-48 \\
\hline Logroscino $^{5}$ & 2008 & 19 & $16-31$ & 30 & $27-39$ \\
\hline Logroscino $^{16}$ & 2010 & 9 & May-14 & NM & NM \\
\hline Turner $^{17}$ & $2010 a$ & 15 & $2-216$ & 41 & $33-49$ \\
\hline Turner ${ }^{18}$ & $2010 b$ & 9 & Feb-34 & 27 & $20-34$ \\
\hline Fujimura-Kiyono ${ }^{19}$ & 2011 & 14 & NM & 32 & Mar-60 \\
\hline Chió $^{20}$ & $2011 a$ & 9 & May-14 & NM & NM \\
\hline Chió21 & $2011 b$ & NM & NM & 46 & $40-53$ \\
\hline Roche $^{22}$ & 2012 & NM & NM & 42 & NM \\
\hline $\operatorname{Lee}^{6}$ & 2013 & NM & NM & 66 & $59-82$ \\
\hline Favero et al. (this article) & 2013 & 14 & Oct-24 & 19 & Sep-41 \\
\hline
\end{tabular}

NM: not mentioned. 

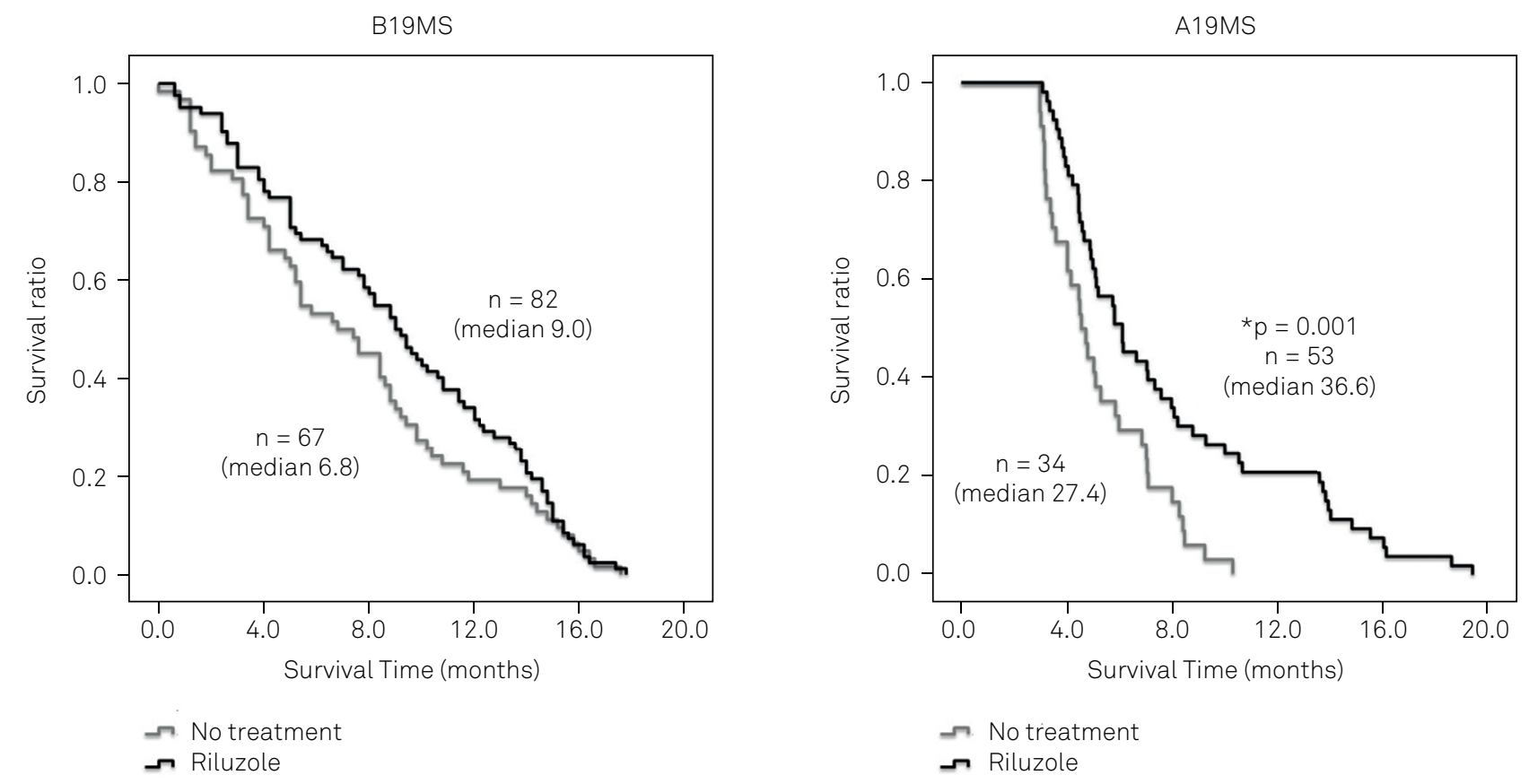

Figure 2. Survival time of ALS patients who did, or did not, receive riluzole.

We found a difference between males, but not between females when we compared the effect of riluzole. In the A19 group, males treated with riluzole showed a higher survival rate (19.9 months) than the ones who were not medicated (14.2 months, $\mathrm{p}=0.004$ ). The diagnosis before (Figure 3A, D), at (Figure 3B, E) or after (Figure 3C, F) the first appointment with the neurologist and the response to riluzole differed in the B19 and A19 groups. In the A19 group, patients who received the prescription of riluzole at the first appointment showed longer survival times (15.0 months) compared with those who were not treated with this drug (9.6 months, $\mathrm{p}<0.001$ ) (Figure 3E).

The topography of the first symptoms (upper limbs, lower limbs and bulbar onset) and the response to riluzole differed in the B19 (Figure 4A, B and C) and A19 groups (Figure 4D, E and F). In the B19 group, patients treated with riluzole showed longer survival times (5.3 months), compared with patients who did not take the medication (2.6 months, $p=0.010$ ) (Figure $4 \mathrm{C})$. In the A19 group, patients with bulbar onset treated with riluzole showed shorter survival times (18.3 months) than the ones who did not receive the medication (9.5 months, $\mathrm{p}<0.001$ ) (Figure 4D).

\section{Riluzole and non-invasive ventilation prescriptions}

In the B19 group $(\mathrm{n}=144), 62$ patients did not receive a riluzole prescription (12 without noninvasive ventilation and 50 with noninvasive ventilation) and 82 patients were treated with riluzole (eight without noninvasive ventilation and 74 with noninvasive ventilation). The chi-square test showed that there was no difference in the number of patients with noninvasive ventilation in the subgroups with or without riluzole prescription $(\mathrm{p}=0.101)$.

In the A19 group ( $\mathrm{n}=87), 34$ patients did not receive the prescription of riluzole (two without noninvasive ventilation and 32 with noninvasive ventilation) and 53 patients were treated with riluzole (six without noninvasive ventilation and 47 with noninvasive ventilation). The chi-square test showed that there was no difference in the number of patients with noninvasive ventilation in the subgroups with or without riluzole prescription $(\mathrm{p}=0.391)$.

\section{DISCUSSION}

The present study investigated epidemiological and clinical factors that could be influenced by the treatment with riluzole. The survival rate depends not only on the treatment with riluzole, but also on populational characteristics and studies inclusion/exclusion criteria ${ }^{21,23}$. Many factors may interfere with the ALS prognosis and interact with the effect of riluzole, e.g. nonspecific symptoms in early stages, the type of clinical impairment, time between the first symptoms and the first appointment with a neurologist, and the time before the start of treatment (medication/rehabilitation).

A high number of patients died before 19 months. Considering the follow-up time (from the first symptoms to death) and the survival time (from the diagnosis to death), differences favoring the A19 group were found: patients diagnosed in the early stages and patients presenting with their first symptoms in their lower limbs survived longer. 

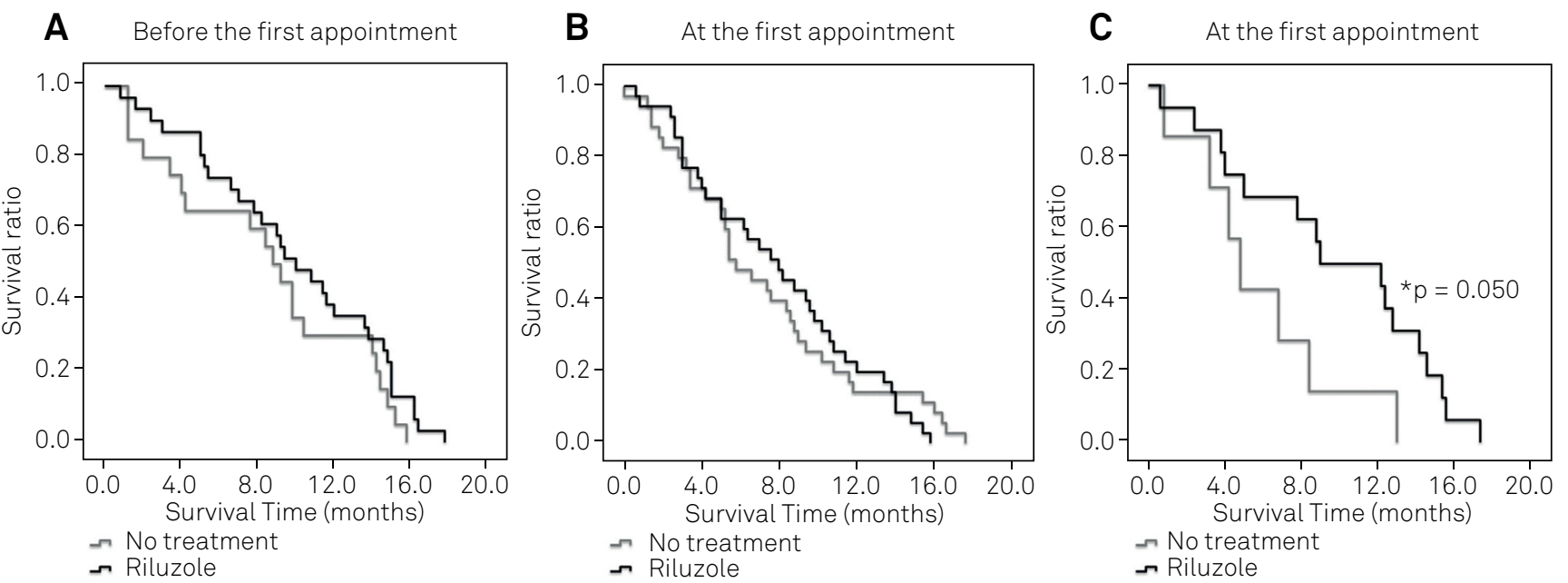

Survival above than 19 months (A19MS)
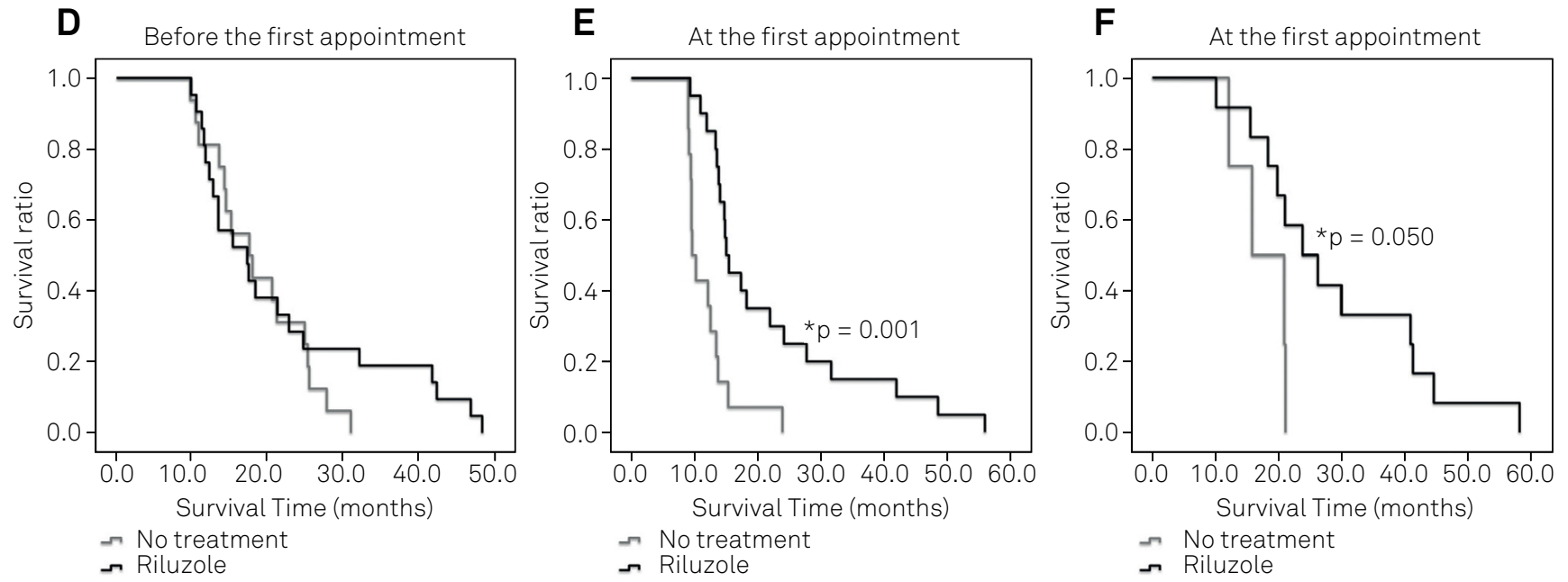

Figure 3. Moment of diagnosis.

Many patients showed severe clinical impairment in the first clinical evaluation. This means that there was a long interval between the first symptoms and the first appointment (from 10 to 24 months, median: 14 months). The late diagnosis and the more severe impairments shown on the first neurological assessment may have contributed to a shorter survival time. Clinical studies showed that survival time is shorter in more impaired patients ${ }^{4,15}$.

Many studies showed that patients with ALS treated with riluzole (50 mg/twice a day) survive longer ${ }^{6,15,23}$. Lee et al. ${ }^{6}$ showed that the mortality rate among patients receiving riluzole was reduced by almost $66 \%$. However, patients who started treatment with severe and generalized clinical impairment had less benefit from riluzole. The glutamatergic action of riluzole depends on viable motor neuron activity. Therefore, if a high number of neurons is damaged, the riluzole does not show significant effects ${ }^{24}$. Bensimon et al. ${ }^{25}$ showed that the survival rate after 12 months was significantly higher for patients receiving riluzole, compared to those receiving placebo. Miller et al. ${ }^{23}$ reported that riluzole may have beneficial effects on bulbar and limb functions, but not on muscle strength.

\section{Epidemiological characteristics}

In the present study, the median age of the B19 group was 63 and of the A19 group was 57 years old $(p<0.050)$. The study by Palermo et al. ${ }^{2}$ found a lower mean age in a Brazilian sample (52 years of age). A retrospective study with 1,226 patients with ALS showed a median survival time of 25 months (range: 16-34 months) and described an age difference, benefiting younger patients on clinical presentation, survival rate and functional independence ${ }^{13}$. Mandrioli et al. ${ }^{7}$, Zoccolella et al..$^{15}$ and Lee et al. ${ }^{6}$ also associated a greater age with a lower survival rate. Zoccolella et al. ${ }^{15}$ mentioned that 
older patients, although showing lower survival rates, had more benefits from riluzole.

The survival rate differed between men and women. Matos et al. ${ }^{26}$ compared the mortality of men and women: 158 men versus 168 women with ALS, which resulted in no significant gender differences. Mandrioli et al. ${ }^{7}$ mentioned no gender influence on survival rate. On the contrary, the present study found 127 men (55\%) and 104 women (45\%) with ALS. This predominance of males agrees with the studies by Lee et al. ${ }^{6}$, McCombe and Henderson ${ }^{3}$, Zoccolella et al. ${ }^{15}$, Argyriou et al. ${ }^{1}$, Palermo et al. ${ }^{2}$ and Logroscino et al. ${ }^{4,5,16}$. Some studies reported that this male preponderance is due to heavy industries and agricultural jobs ${ }^{1,3,6,7}$. However, some authors did not find this difference. Matos et al. ${ }^{26}$ and Werneck et al. ${ }^{27}$ compared the incidence of ALS among men and women. They analyzed death certificates and hospital charts from two different regions of Brazil and found no gender differences.

The influence of gender on survival rate is controversial in the literature. McCombe and Henderson ${ }^{3}$ stated that gender did not show a clear effect on survival. The study by Lee et al. ${ }^{6}$ showed lower survival rates in men, compared to women. This could be explained by a toxic effect of a mutant SOD1 protein in the cerebrospinal fluid in men $^{28}$. Norris et al. ${ }^{29}$ stated that gender differences diminished with increasing age. In contrast, Aguila et al. ${ }^{9}$ found that an older age and female gender were strongly associated with lower survival rates, and Norris et al. ${ }^{29}$ reported that women may show the first symptoms of ALS later in life than men, but men may experience longer courses with milder paralysis than women.
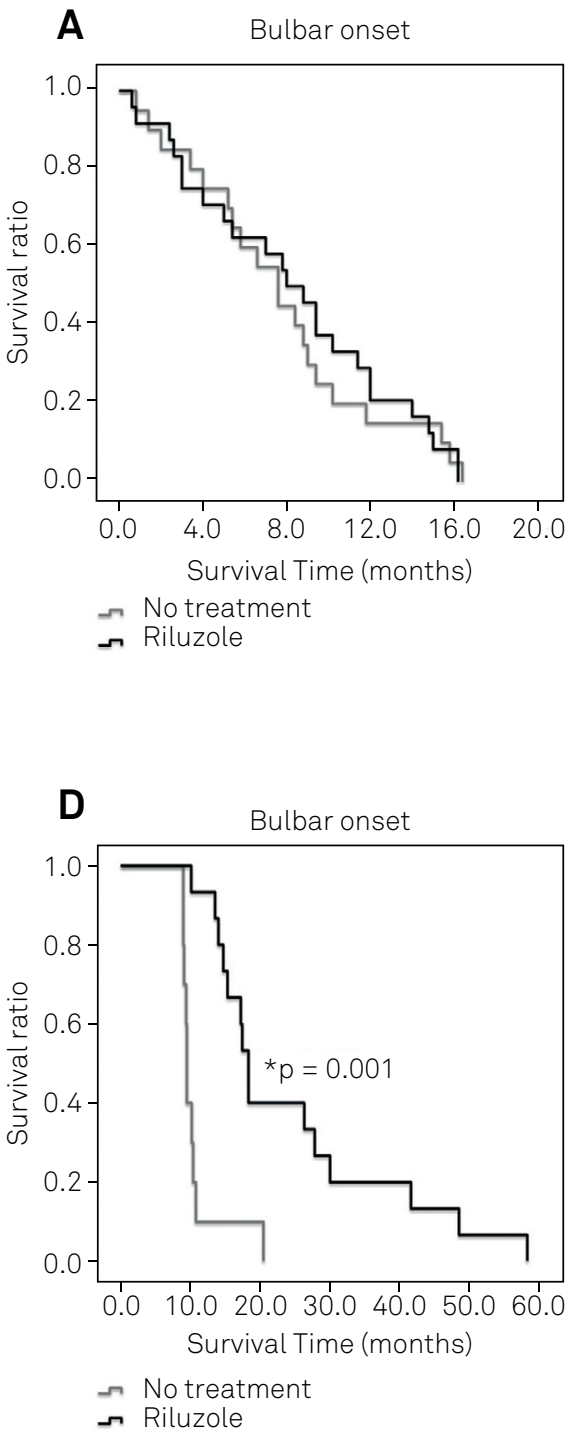

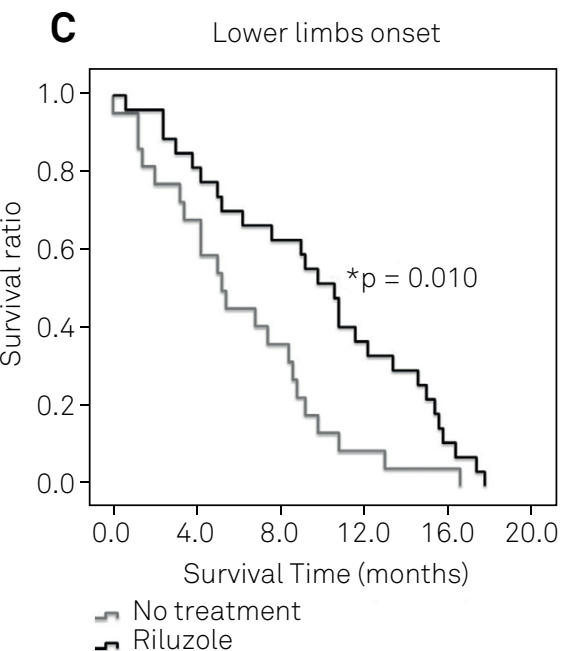

Survival above than 19 months (A19MS)

E

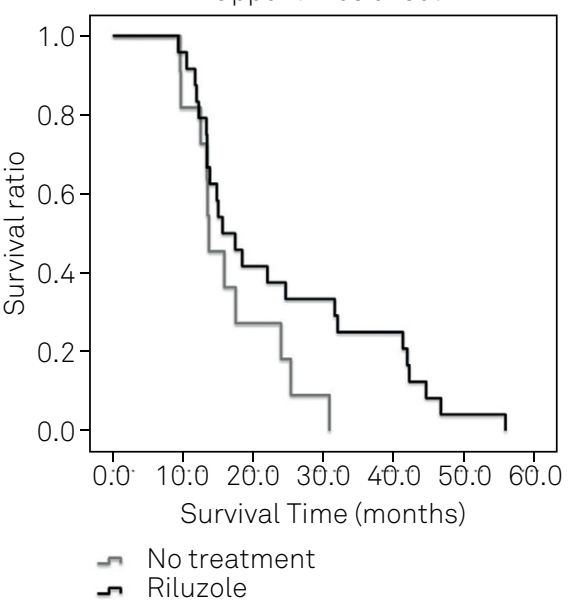

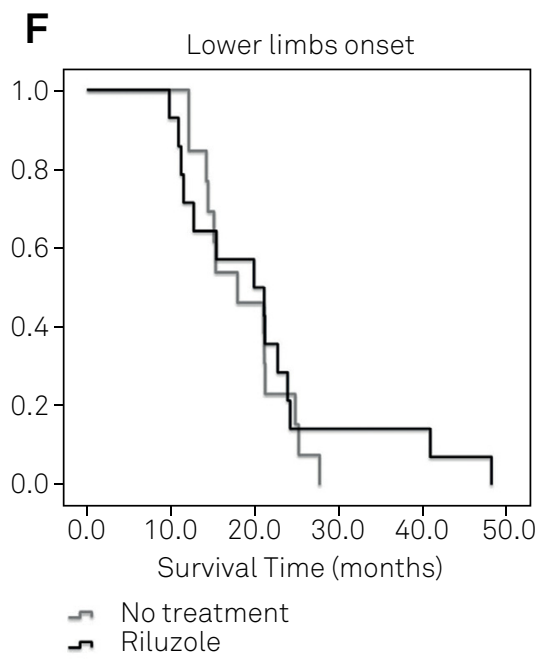


Nygren et al. ${ }^{30}$ described that women were less frequently treated with riluzole than men. The lower frequency of prescription of riluzole among women may have influenced the survival rates of women and men in studies by both Aguila et al. ${ }^{9}$ and Nygren et al. ${ }^{30}$. Another possible explanation is that men can take longer than women to see a neurologist, and show more typical symptoms in the first visit due to ALS progression. On the other hand, women may visit the physician too early, with nonspecific symptoms, which results in a longer time interval before diagnosis.

\section{The effects of symptoms topography and riluzole on survival rates}

We observed a positive effect of riluzole in the B19 group, in patients with lower limb onset. These patients may have survived longer because this topography has a less aggressive time course, with a bottom-up evolution. Zoccolella et al. ${ }^{15}$ and Mandrioli et al. ${ }^{7}$ observed that lower limb onset was associated with longer survival than upper limb and bulbar onsets. Lower limb onset shows a longer progression and higher survival rates because the motor neurons that are close to the ones degenerating are affected. Therefore, the propagation of clinical manifestations occurs contiguously, and it takes longer to impair spinal and bulbar structures related to vital functions (breathing, swallowing) ${ }^{17,20}$.

The bulbar phenotype seems to interact with age. According to Norris et al. ${ }^{29}$, the risk of a bulbar onset and lower survival rate increases with age. Turner et al. ${ }^{18}$, conversely, described survival rates in bulbar onset ALS as highly variable, and Chiò et al. ${ }^{21}$ stated that age at onset is higher in the bulbar phenotype.

In the A19 group, riluzole benefited patients with bulbar onset. As bulbar manifestations are usually the most evident, although diagnostic confirmation may be more difficult, the search for a physician may have occurred earlier. This may have favored an earlier therapeutic intervention, justifying a better response in the group treated with riluzole. Zoccolella et al. ${ }^{15}$ verified a more evident effect of riluzole in bulbar onset ALS patients than in limb onset patients.

Not only riluzole, but also therapies to provide a better physical and respiratory condition, may also have contributed to a longer survival of the A19 group. Noninvasive ventilation treats respiratory insufficiency and percutaneous endoscopic gastrostomy can stabilize weight. These actions prolong survival in patients with $\mathrm{ALS}^{23}$. Czell et al. ${ }^{31}$ verified that the association of noninvasive ventilation and percutaneous endoscopic gastrostomy in ALS patients with moderate to severe impaired ventilation may have beneficial outcomes, even in ALS patients with severe respiratory impairment.

\section{The effects of the time of diagnosis and riluzole on survival rates}

In the B19 and A19 groups, patients diagnosed after the first appointment benefited from riluzole. In the A19 group, patients diagnosed at the first appointment also showed a significant positive effect of riluzole on survival time. These patients may have had longer early stage times, less generalized clinical impairment and, consequently, slower ALS progression. Therefore, they took longer to seek medical assistance. However, more severe patients benefited from early diagnosis and treatment. Ludolph and Jesse ${ }^{24}$ stated that the early diagnosis may have been the major reason for the change in the ALS prognosis.

Seven patients were not assessed with electromyography before the first appointment with the neurologist and survived longer than those with electromyography results compatible or not compatible with ALS. We believe that patients without a defined diagnosis after the appointment with the neurologist were probably less affected clinically. The diagnosis at that moment was not possible, and a longer time was needed to define and confirm the diagnosis. Besides, in the public health system in Brazil, the early diagnosis of ALS may be challenging due to socioeconomic problems and this may negatively influence clinical outcomes. Therefore, the median of the total survival time was lower than in other studies.

As a limitation of this study, we must mention that information about sleep studies and gastrostomy was not available and may have influenced the survival rates. Future studies should investigate the influence of these variables in ALS survival.

In conclusion, gender, first symptoms topography and the moment of diagnosis affected the prognosis of patients with ALS. The benefits of riluzole were influenced by epidemiological and clinical factors.
1. Argyriou AA, Polychronopoulos P, Papapetropoulus S, Ellul J, Andriopoulos I, Katsoulas G et al. Clinical and epidemiological features of motor neuron disease in south-western Greece. Acta Neurol Scand. 2005;111(2):108-13. https://doi.org/10.1111/j.1600-0404.2004.00362.x

2. Palermo S, Lima JMB, Alvarenga RP. Epidemiology of amyotrophic lateral sclerosis - Europe/North

America/South America/Asia: discrepancies and similarities: systematic review of the literature]. Rev Bras Neurol. 2009;45(2):5-10. Portuguese.
3. McCombe PA, Henderson RD. Effects of gender in amyotrophic lateral sclerosis. Gend Med. 2010;7(6):557-70. https://doi.org/10.1016/j.genm.2010.11.010

4. Logroscino G, Beghi E, Zoccolella S, Palagano R, Fraddosio A, Simone IL et al. Incidence of amyotrophic lateral sclerosis in southern Italy: a population based study. J Neurol Neurosurg Psychiatry. 2005;76(8):1094-8. https://doi.org/10.1136/jnnp.2004.039180 
5. Logroscino G, Traynor BJ, Hardiman O, Chio' A, Couratier P, Mitchell JD et al. Descriptive epidemiology of amyotrophic lateral sclerosis: new evidence and unsolved issues. J Neurol Neurosurg Psychiatry. 2008;79(1):6-11. https://doi.org/10.1136/jnnp.2006.104828

6. Lee CT, Chiu YW, Wang KC, Hwang CS, Lin KH, Lee IT et al. Riluzole and prognostic factors in amyotrophic lateral sclerosis long-term and short-term survival: a population-based study of 1149 cases in Taiwan. J Epidemiol. 2013;23(1):35-40. https://doi.org/10.2188/jea.JE20120119

7. Mandrioli J, Faglioni P, Nichelli P, Sola P. Amyotrophic lateral sclerosis: prognostic indicators of survival. Amyotroph Lateral Scler. 2006;7(4):217-26. https://doi.org/10.1080/17482960600947648

8. Wilbourn AJ. Clinical neurophysiology in the diagnosis of amyotrophic lateral sclerosis: the Lambert and the El Escorial criteria. J Neurol Sci. 1998;160 Suppl 1:S25-9. https://doi.org/10.1016/S0022-510X(98)00194-4

9. Aguila MAD, Longstreth WT Jr, McGuire V, Koepsell TD, Belle G. Prognosis in amyotrophic lateral sclerosis: a population-based study. Neurology. 2003;60(5):813-9. https://doi.org/10.1212/01.WNL.0000049472.47709.3B

10. Dietrich-Neto F, Callegaro D, Dias-Tosta E, Silva HA, Ferraz ME, Lima JM et al. Amyotrophic lateral sclerosis in Brazil: 1998 national survey. Arq Neuropsiquiatr. 2000;58(3A):607-15. https://doi.org/10.1590/S0004-282X2000000400002

11. Tomik B, Nicotra A, Ellis CM, Murphy C, Rabe-Hesketh S, Parton M et al. Phenotypic differences between African and white patients with motor neuron disease: a case-control study.J Neurol Neurosurg Psychiatry. 2000;69(2):251-3. https://doi.org/10.1136/jnnp.69.2.251

12. Traynor BJ, Alexander M, Corr B, Frost E, Hardiman O. Effect of a multidisciplinary amyotrophic lateral sclerosis (ALS) clinic on ALS survival: a population based study, 1996-2000. J Neurol Neurosurg Psychiatry. 2003;74(9):1258-61. https://doi.org/10.1136/jnnp.74.9.1258

13. Forbes RB, Colville S, Cran GW, Swingler RJ. Unexpected decline in survival from amyotrophic lateral sclerosis/motor neurone disease. J Neurol Neurosurg Psychiatry. 2004;75(12):1753-5. https://doi.org/10.1136/jnnp.2003.02436

14. Beghi E, Logroscino G, Chiò A, Hardiman O, Mitchell D, Swingler R et al. The epidemiology of ALS and the role of population-based registries. Biochim Biophys Acta 2006;1762(11-12):1150-7. https://doi.org/10.1016/j.bbadis.2006.09.008

15. Zoccolella S, Beghi E, Palagano G, Fraddosio A, Guerra V, Samarelli $V$ et al. Riluzole and amyotrophic lateral sclerosis survival: a population-based study in southern Italy. Eur J Neurol. 2007;14(3):262-8. https://doi.org/10.1111/j.1468-1331.2006.01575.x

16. Logroscino G, Traynor BJ, Hardiman O, Chiò A, Mitchell D, Swingler RJ et al. Incidence of amyotrophic lateral sclerosis in Europe. J Neurol Neurosurg Psychiatry. 2010;81(4):385-90. https://doi.org/10.1136/jnnp.2009.183525

17. Turner MR, Brockington A, Scaber J, Hollinger $H$, Marsden R, Shaw PJ et al. Pattern of spread and prognosis in lower limb-onset ALS. Amyotroph Lateral Scler. 2010;11(4):369-73. https://doi.org/10.3109/17482960903420140
18. Turner MR, Scaber J, Goodfellow JA, Lord ME, Marsden R, Talbot K. The diagnostic pathway and prognosis in bulbar-onset amyotrophic lateral sclerosis. J Neurol Sci. 2010;294(1-2):81-5. https://doi.org/10.1016/j.jns.2010.03.028

19. Fujimura-Kiyono C, Kimura F, Ishida S, Nakajima H, Hosokawa T, Sugino $\mathrm{M}$ et al. Onset and spreanding patterns of lower motor neuron involvements predict survival in sporadic amyotrophic lateral sclerosis. J Neurol Neurosurg Psychiatry. 2011;82(11):1244-9. https://doi.org/10.1136/jnnp-2011-300141

20. Chiò A, Calvo A, Moglia C, Mazzini L, Mora G. Phenotypic heterogeneity of amyotrophic lateral sclerosis: a population based study. J Neurol Neurosurg Psychiatry. 2011;82(7):740-6. https://doi.org/10.1136/jnnp.2010.235952

21. Chiò A, Canosa A, Gallo S, Cammarosano S, Moglia C, Fuda G et al. ALS clinical trials: do enrolled patients accurately represent the ALS population? Neurology. 2011;77(15):1432-7. https://doi.org/10.1212/WNL.0b013e318232ab9b

22. Roche JC, Rojas-Garcia R, Scott KM, Scotton W, Ellis CE, Burman R et al. A proposed staging system for amyotrophic lateral sclerosis. Brain. 2012;135(3):847-52. https://doi.org/10.1093/brain/awr351

23. Miller RG, Mitchell JD, Lyon M, Moore DH. Riluzole for amyotrophic lateral sclerosis (ALS)/motor neuron disease (MND). Cochrane Database Syst Rev. 2002;(2):CDD001447. https://doi.org/10.1002/14651858.CD001447

24. Ludolph AC, Jesse S. Evidence-based drug treatment in Amyotrophic lateral sclerosis and upcoming clinical trials. Ther Adv Neurol Disorder. 2009;2(5):319-26. https://doi.org/10.1177/1756285609336399

25. Bensimon G, Lacomblez L, Meininger V. A controlled trial of riluzole in amyotrophic lateral sclerosis. N Engl J Med. 1994;330(9):585-91. https://doi.org/10.1056/NEJM199403033300901

26. Matos SE, Conde MTRP, Fávero FM, Taniguchi M, Quadros AA, Fontes SV et al. Mortality rates due to amyotrophic lateral sclerosis in São Paulo City from 2002 to 2006. Arq Neuropsiquiatr. 2011;69(6):8616. https://doi.org/10.1590/S0004-282X2011000700002

27. Werneck LC, Bezerra R, Silveira Neto O, Scola RH. A clinical epidemiological study of 251 cases of amyotrophic lateral sclerosis in the south of Brazil. Arq Neuropsiquiatr. 2007;65(2A):189-95. https://doi.org/10.1590/S0004-282X2007000200001

28. Frutiger K, Lukas TJ, Gorrie G, Ajroud-Driss S, Siddique T. Gender difference in levels of $\mathrm{Cu} / \mathrm{Zn}$ superoxide dismutase (SOD1) in cerebrospinal fluid of patients with amyotrophic lateral sclerosis. Amyotroph Lateral Scler. 2008;9(3):184-7. https://doi.org/10.1080/17482960801984358

29. Norris F, Shepherd R, Denys E, U K, Mukai E, Elias L et al. Onset, natural history and outcome in idiopathic adult motor neuron disease. J Neurol Sci. 1993;118(1):48-55. https://doi.org/10.1016/0022-510X(93)90245-T

30. Nygren I, Antonova K, Mattsson P, Askmark H. The ALS/MND prevalence in Sweden estimated by riluzole sales statistics. Acta Neurol Scand. 2005;111(3):180-4. https://doi.org/10.1111/j.1600-0404.2005.00384.x

31. Czell D, Bauer M, Binek J, Schoch OD, Weber M. Outcomes of percutaneous endoscopic gastrostomy tube insertion in respiratory impaired amyotrophic lateral sclerosis patients under noninvasive ventilation. Respir Care. 2013;58(5):838-44. https://doi.org/10.4187/respcare.02024. 


\section{Erratum}

Epidemiological and clinical factors impact on the benefit of riluzole in the survival rates of patients with ALS Arq Neuropsiquiatr 2017;75(8):515-522. http://dx.doi.org/10.1590/0004-282x20170083

\section{The columns RANGE of the table:}

Table. Time intervals (median, in months) between the first symptoms and the diagnosis, and between the diagnosis and death

\begin{tabular}{|c|c|c|c|c|c|}
\hline Authors & Year & First symptoms to diagnosis & Range & Diagnosis to death (survival) & Range \\
\hline Dietrich-Neto ${ }^{10}$ & 2000 & 11 & $0-332$ & 42 & $7-191$ \\
\hline Tomik $^{11}$ & 2000 & NM & NM & 38 & $10-218$ \\
\hline Aguila $^{9}$ & 2003 & 32 & NM & 19 & NM \\
\hline Traynor $^{12}$ & 2003 & 10 & $1-110$ & NM & NM \\
\hline Forbes $^{13}$ & 2004 & 15 & Jun-17 & 28 & $17-50$ \\
\hline Mandrioli & 2006 & 9 & NM & 29 & NM \\
\hline Beghi ${ }^{14}$ & 2006 & 39 & NM & 30 & NM \\
\hline Zoccolella ${ }^{15}$ & 2007 & 8 & Jan-70 & 18 & Jan-48 \\
\hline Logroscino $^{5}$ & 2008 & 19 & $16-31$ & 30 & $27-39$ \\
\hline Logroscino $^{16}$ & 2010 & 9 & May-14 & NM & NM \\
\hline Turner $^{17}$ & $2010 a$ & 15 & $2-216$ & 41 & $33-49$ \\
\hline Turner ${ }^{18}$ & $2010 b$ & 9 & Feb-34 & 27 & $20-34$ \\
\hline Fujimura-Kiyono ${ }^{19}$ & 2011 & 14 & NM & 32 & Mar-60 \\
\hline Chió20 & $2011 a$ & 9 & May-14 & NM & NM \\
\hline Chió ${ }^{21}$ & $2011 b$ & NM & NM & 46 & $40-53$ \\
\hline Roche 22 & 2012 & NM & NM & 42 & NM \\
\hline $\operatorname{Lee}^{6}$ & 2013 & NM & NM & 66 & $59-82$ \\
\hline Favero et al. (this article) & 2013 & 14 & Oct-24 & 19 & Sep-41 \\
\hline
\end{tabular}

NM: not mentioned.

\section{Should be:}

Table. Time intervals (median, in months) between the first symptoms and the diagnosis and between the diagnosis and death.

\begin{tabular}{|c|c|c|c|c|c|}
\hline Authors & Year & First symptoms to diagnosis & Range & Diagnosis to death (survival) & Range \\
\hline Dietrich-Neto ${ }^{10}$ & 2000 & 11 & $0-332$ & 42 & $7-191$ \\
\hline Tomik $^{11}$ & 2000 & NM & NM & 38 & $10-218$ \\
\hline Aguila ${ }^{9}$ & 2003 & 32 & NM & 19 & NM \\
\hline Traynor ${ }^{12}$ & 2003 & 10 & $1-110$ & NM & NM \\
\hline Forbes $^{13}$ & 2004 & 15 & $6-17$ & 28 & $17-50$ \\
\hline Mandrioli ${ }^{7}$ & 2006 & 9 & NM & 29 & NM \\
\hline Beghi ${ }^{14}$ & 2006 & 39 & NM & 30 & NM \\
\hline Zoccolella ${ }^{15}$ & 2007 & 8 & $1-70$ & 18 & $1-48$ \\
\hline Logroscino $^{5}$ & 2008 & 19 & $16-31$ & 30 & $27-39$ \\
\hline Logroscino $^{16}$ & 2010 & 9 & $5-14$ & NM & NM \\
\hline Turner ${ }^{17}$ & $2010 a$ & 15 & $2-216$ & 41 & $33-49$ \\
\hline Turner $^{18}$ & $2010 b$ & 9 & $2-34$ & 27 & $20-34$ \\
\hline Fujimura-Kiyono ${ }^{19}$ & 2011 & 14 & NM & 32 & $3-60$ \\
\hline Chió $^{20}$ & $2011 a$ & 9 & $5-14$ & NM & NM \\
\hline Chió21 & $2011 b$ & NM & NM & 46 & $40-53$ \\
\hline Roche 22 & 2012 & NM & NM & 42 & NM \\
\hline Lee $^{6}$ & 2013 & NM & NM & 66 & $59-82$ \\
\hline Favero & 2013 & 14 & $10-24$ & 19 & $9-41$ \\
\hline
\end{tabular}

